\title{
Corruption in the Middle East Management Implications at a Qatar Construction Project
}

\author{
Paul James \\ Graduate School, Bangkok University, Bangkok, Thailand \\ E-mail: paul.j@bu.ac.th
}

Received: July 4, 2015 Accepted: August 4, 2015 Published: October 8, 2015

doi:10.5296/jmr.v7i5.8379

URL: http://dx.doi.org/10.5296/jmr.v7i5.8379

\begin{abstract}
This is a research paper focused on assessing the level of corruption and its impacts on a construction project relating to a metro project in Qatar. In order to consider more implicitly the questions and issues raised, this empirical groundwork utilised an interpretive perspective. The scope for this research was the on-site contractor team. The population for this study was made up of a number of individuals (32) lower-managers and engineers located at one main-site, and a total of 14lower managers/engineers were determined as the resultant sample frame. The outcomes consisted of six (6) main themes, namely: Country Issues; Company Policies; Management Control; Cost Issues; Documentary Issues; and Financial Demands, raised from an initial research question. The paper gives a clear insight into the practical issues surrounding a metro project assessment. The paper also addresses some of the implications for continuing project construction site developments. The paper suggests that projects of this kind may benefit from a greater use of targeted processes to alleviate corruption possibilities in the construction phase of a project. Very little research has been conducted in this area and the paper exposes weak aspects of the project management capability in Qatar relating to corruption practices unexplored in today's metro project construction environments.
\end{abstract}

Keywords: Corruption, Management, Middle East, Qatar, Construction, Project 


\section{Introduction}

This is an inquiry of the behaviour of management/administrative elements of a construction project in Doha, Qatar. According to Transparency International, Qatar is designated No. 26 in 2014 (TI, 2015) in the world corruption perception index. However, all countries have some corruption elements within its infrastructure operations - the determination is whether this is part of the overall culture or just a sporadic outcome from say large infrastructure events such as for the World Cup. It has been stated (PWC, 2015) that nearly half $(49 \%)$ of the respondents reporting economic crime includes bribery and corruption; and that " $76 \%$ tops the list of types of economic crime experienced by engineering \& construction respondents... and were perpetrated by insiders". Bribery and corruption is therefore a real threat to appropriate and consistent internal governance management (Chang, 2015; James, 2014)of construction projects in the Middle East. However, officially, Qatar remains the top nation in the Middle East and this means corruption is considered a low risk factor (Ramady, 2014). This research follows out from these assertions. Of further issue is the backdrop of the FIFA corruption issues that pervade the media (BBC.com, 2015). Subsequently, there are the reports of fraud among cases (International Anti Corruption Resource Center, 2015) targeted to international development projects, sponsored by the West, that state clearly that $\$ 2.7$ billion a day is paid in bribes across the world, where the most common schemes are bribery. With the little experience Qatar has in managing bribery and corruption - since legislation has only been introduced since 2013 -the possibility is that corruption appears more significantly in Dohathan is being assessed for. For example, ANTICORRP (2015) suggests that utilising a different definition would make Qatar look very different in the world corruption rankings and therefore "challenges its anti-corruption index rankings" (Khatib, 2013). To understand this point further, there are 3 popular world rankings of corruption - each designed to address different issues surrounding the focus for each ranking table (Askari, Rehman and Arfaa, 2010), but there are many more. Another issue is that all the projects for the 2022 World Cup - amounting to US\$60Bn - are totally government driven and government financed (Moubaydeen, 2013) the process of which is often predisposed with corruptive risk practices. Qatar is not considered a rules-based culture but a relationship-based culture (Hooker, 2009), which affords different perspectives on contract operations and issues relating from non-performance or non-compliance. Also this means that better developed and designed projects often "fail" because the available resources would be soaked up during the design, construction and commissioning process leaving little room for "loose money" that is undocumented and syphoned off in a veil of secrecy.Researchers have stated that corruption in any form is unacceptable and deleterious to a project - irrespective of the notion of benefits (World Bank, 2004).

\section{Corruption in Construction Projects}

Corruption is often defined as the misuse of finances (project) for personal gain (OECD, 2015) and is empirically, factually or mandated to be utilised to influence another to their viewpoint or to support them. Ernst and Young (http://www.ey.com, 2015) indicate quite clearly that the potential for corruption is high in construction projects and is considered rife in Qatar despite Qatar signing the UNCAC agreement in 2005 (UNCAC, 2015). However, it 
would appear that little progress has been made, with a new anti-corruption committee that was created to review and monitor corruption - including at construction projects. Corruption is therefore one of the main risks associated with managing large infrastructure projects (Al-Sabah, Menassa \& Hanna, 2014). There would appear to be little reporting of corruption in construction projects in Qatar, which may reflect other aspects of the reporting process being made intentionally unclear or avoiding such reporting altogether (Ramady, 2014). The level of reporting avoidance is something that cannot be substantiated formally, but it does remain an additional risk factor (Stansbury, 2005).

This creates the context for the research question, What is the managerial impact of the various corruption practices in complex construction projects in Qatar?

\section{Methodology}

To investigate the issues generated within the site construction context, a deeper, more involved approach was considered appropriate that required personal discussions on such critical and important issues. In order to consider more implicitly these generated issues, this empirical foundation exploited an interpretive approach (Hill, Thompson \& Williams, 1997; Walsh, White \& Young, 2008). Corruption is a pervasive activity, as it cannot be talked about in the free light of day. It is therefore an area of interest where the qualitative methodology is most appropriate to generate this type of data.

This was an attempt to understand the perceptions of site staff/lower engineers of their site experiences. The site staff/lower engineers were considered specialist knowledge agents and actors (Benn et al., 2008) as their opinions and experiences influenced the perception of corruption practices, and the development and application of building appropriate site management knowledge.

The research used a semi-structured interview conducted with site staff/lower engineers, who provided an appropriate element of context and flexibility (Cassell \& Symon, 2004) and this was further aided by applying an inductive/theory building approach (Glaser \& Strauss, 1967). Given the lack of appropriately focused research in this area, this methodology is seen as suitable for creating contextual data for the purpose of forming richer theory development (Cayla \& Eckhardt, 2007). A pilot study was carried out that allowed the changes to language and questions that had more meaning and understanding by the respondents (Kim, 2011). This led to a greater streamlined question regime and an enhanced communication approach with respondents (James \& James, 2011).

The population frame (32) for this study was made up of all site staff/lower engineers who had responsibility for managing the site and situate at one office location, which is considered an existing frame (Ritchie \& Lewis, 2003) and delivered an initial means for appropriate sampling assessment with clear boundaries (Coyne, 1997). Given that not all individuals in this group were available for interview, the sampling frame was configured from this population as being described as 22 in number, where each respondent was included (Fink, 2000), and no respondent was considered out of scope relative to the research orientation and requirements (Koerber\& McMichael, 2008). Consequently, and in line with a qualitative 
approach (Bryman, 2012), the respondents were chosen through applying the approach of a targeted population of interest (Carman, 1990) and this reflected the criteria of theoretical purpose, relevance and appropriateness (Glaser \& Strauss, 1967).This was considered adequate and appropriate for this inquiry (Guest, Bunce \& Johnson, 2006; and Bryman, 2012), but it had no bearing on the research logic (Crouch \& McKenzie, 2006). Additionally, using Glaser's (2004) sampling processes, a total of 14lower managers/engineers were thus determined as the resultant sample frame, which could also be considered convenience sampling according to Harrel \& Fors (1992) and the sample frame meets the saturation requirements of Guest, Bunce, \& Johnson (2006) and thus takes the sample frame beyond the expected level.

Each interview was audio recorded for future analysis. Interviews were conducted in English and took approximately one hour. All interviews were conducted through Skype and recorded digitally after gaining explicit permission (following Duranti, 2007) and were later transcribed verbatim using NVivo 11 software using the approach indicated by Bailey (2008). The conduct of the interviews follows a similar process used by Gray \& Wilcox (1995) and James (2014), with each individual group being asked the same set of questions - modified through ancillary questioning (probes and follow-ups) in the same way as Balshem (1991). To increase the reliability of the data, the actual transcription was returned to each respondent - via e-mail - for comment, correction, addition or deletion and return, which followed the process of validated referral (Reeves \& Harper, 1981). Whole-process validity was achieved as the respondents were considered widely knowledgeable of the context and content associated with the research orientation (Tull and Hawkins, 1990). Each interview was initially manually interrogated and coded using the Acrobat software according to sub-themes that 'surfaced' from the interview dialogue - using a form of open-coding derived from Glaser (1992a), and Straus and Corbin (1990). This treatment was also reinforced and extended through the use of thematic analysis conducted using the NVivo 11 - qualitative software package (Walsh, White \& Young, 2008). Each interview was treated and coded independently. In this way, no portion of any interview dialogue was left uncoded and the overall outcome represented the shared respondents views and perspectives through an evolving coding-sequence (Buston, 1999). Various themes were sensed from the use of the software packages, as well as from the initial manual-coding attempts. This dual form of interrogation was an attempt to increase the validity of the choice of both key themes and sub-themes through a triangulation process (Onwuegbuzie, Leech \& Collins, 2012). NVivo 11 was further used to explore these sub-themes by helping to pull together each of these sub-themes from all the interviews (Harwood \& Garry, 2003). In this way, it was possible to capture each respondent's comments across transcripts (Riessman, 1993) on each supported sub-theme and place them together for further consideration and analysis (Ryan \& Bernard, 2003).

The structure of the outcome is greatly influenced by the emergence of the key-themes and sub-themes. The preferred strategy for the analysis of the primary data was to use the stated research question, which was used as a guide to providing the outcome (based on Yin, 1994).The research methodology used was considered a mixed methodology approach 


\section{Macrothink}

(James and James, 2011) and was determined to create the best possible narrative of the situation in question. The application of the overall research methodology produces construct validity (Healy and Perry, 2000) (based upon the realism paradigm); and preferring to use the terms of credibility and dependability which are accepted by many qualitative researchers in place of reliability by applying Guba's constructs (Guba, 1981) and leading to the Lincoln and Guba (1985) notion of "progressive subjectivity".

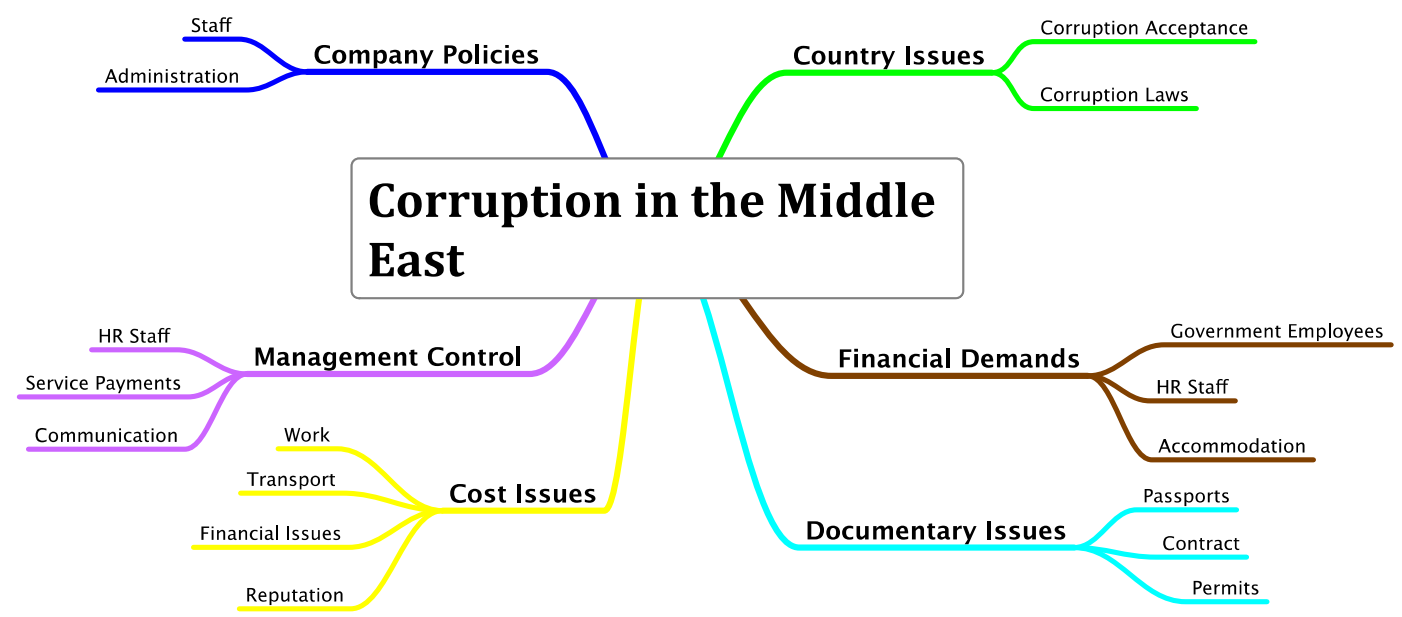

Figure 1. Research outcomes

\subsection{Illustration of Research Outcomes}

The outline of the research outcomes for this study is shown in Figure 1 above. The framework supported by appropriate literature, illustrated below in Table 1, consists of six (6) main themes, and seventeen (17) sub-themes. The outcomes are stated below where the discussion focuses on the sub-theme elements within each key theme. The discussion format used in this paper reflects the respondent's voice through a streamlined and articulated approach for reporting. The style adopted for reporting and illustrating the data is greatly influenced by Gonzalez, (2008) and also Daniels et al. (2007) and is discussed below, focusing on the raised research question and the resultant themes. Table 1, below illustrates the respondent references for each sub-theme. 
Table 1. Research question, themes and references

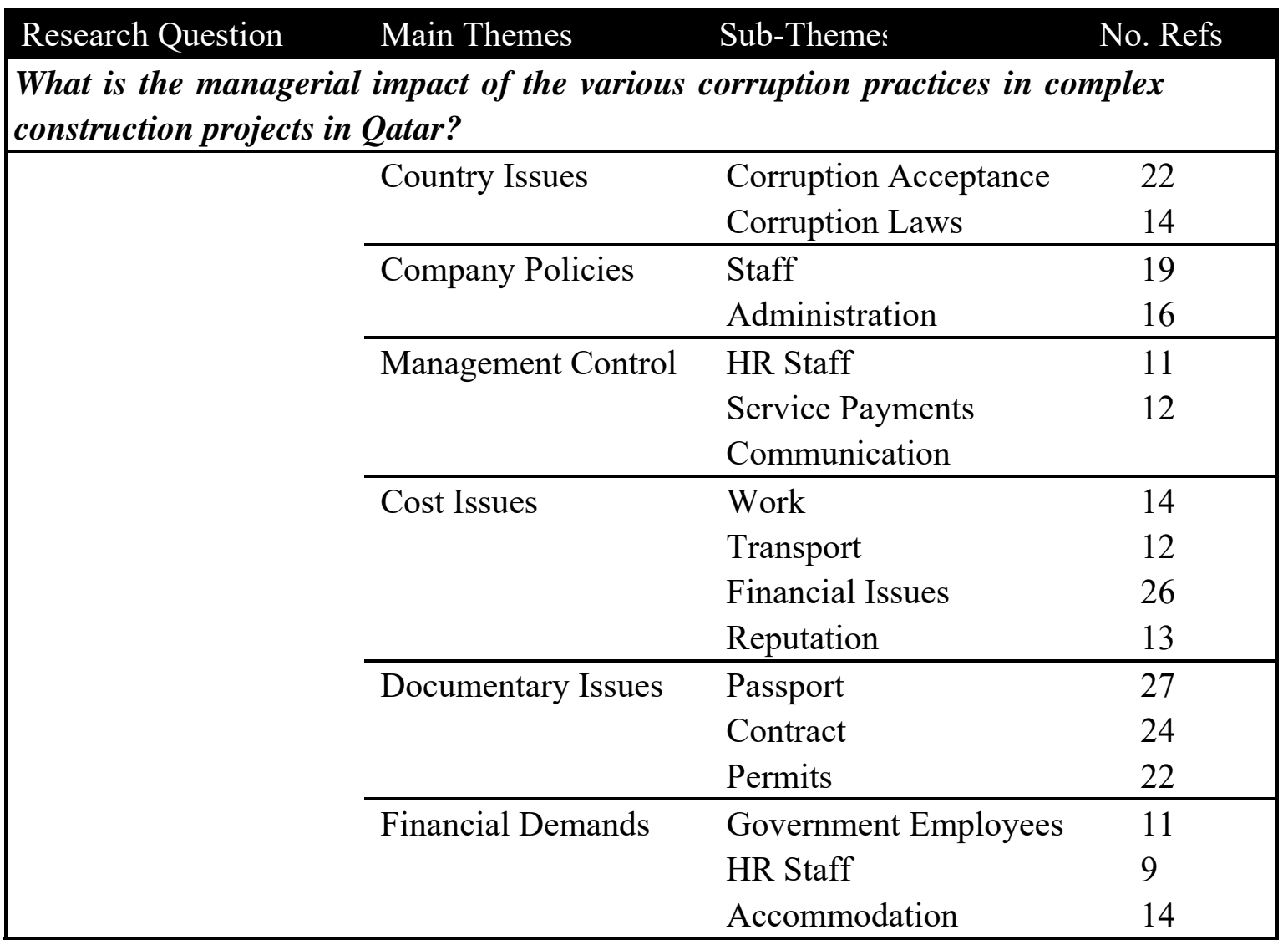

Table 1 above indicates the minimum responses for each identified major theme.

Table 2. Major themes and respondents

\begin{tabular}{|l|l|}
\hline Major Themes & Respondent Number \\
\hline Country Issues & $2,5,7,8,11$ \\
\hline Company Policies & $1,3,6,9,11,13$ \\
\hline Management Control & $2,5,6,9,10,11,13,14$ \\
\hline Cost Issues & $3,4,5,6,7,8,9,10,11,12,14$ \\
\hline Documentary Issues & $1,3,6,7,8,10,11,12,14$ \\
\hline Financial Demands & $2,3,4,5,7,9,10,11,13$ \\
\hline
\end{tabular}

\section{Results}

The results are presented below using the research question as a pointer and supportive empirical evidence through indicated extractions as in Gonzalez, (2008). Consequently, considering the research question - What is the managerial impact of the various corruption practices in complex construction projects in Qatar? The results are stated as six (6) main themes, and seventeen (17) sub-themes as indicated below, where each sub-theme theme is placed with each corresponding main theme. 


\subsection{Country Issues}

The managerial culture of authorities suggests that there is an elitist attitude to their work ethic, which imposes severe constraints on the foreign workforce. In terms of Corruption Acceptance, this is typified by one respondent (2) who suggested that, ...it do not appear to want to interfere with companies who persistently take passports, ID cards or other ID documentary evidence, as a means to control the workforce. Another respondent (7) indicated that, ...corruption is not visible here unless you work with them. Then it becomes very clear...

In terms of Corruption Laws, one respondent (5) stated, ... it is not the culture to point fingers at those in power... ... so they can get away with anything.Another respondent (11) detailed that, ...You cannot exit the country without the company giving a written authorization especially if you raise an issue or make it public. They own you. Another respondent (8) suggested that, ...the laws are there I am sure. But it does not get enforced. They [Qatari] take what they can get.

This suggests quite clearly that the country has to deal with corruption issues and as a country as yet does not appear to show any intent to make any administrative changes.

\subsection{Company Policies}

Company policies affect how staff can act and be treated. In terms of Staff, this is characterized by one respondent (9) who suggested that, ...It is very hard, as you work everyday many hours....They can move, but we can't. Another respondent (1) indicated that, ...Yes sure. They [Qatari's] just asks for money for anything you want them to do. Even if they are salaried with you. Another respondent (11) indicated that, ...HR can only do what they are told. So it is the company that asks for money, not just HR. Everybody's mooching for more money from us. It's just not right. They don't look after us at all.

In terms of Administration, which is typified by one respondent (13) who suggested that,...When you leave a job, the first thing that hits you is the hotel or accommodation manager asks for your credit card to pay for the accommodation otherwise they call the police and you get taken to a cell for a few days until you give in. Even if you get out of the country it is very difficult to get that money back. This is corruption right in your face as the police are paid to ensure they get the money. Another respondent (6) indicated that, ...If you leave the project early, they get really upset and won't give you your passport back or sign a paper for you to get out of the country - unless they are paid extra. Your trapped. They extort money from you. This aspect is further supported by another respondent (3) who stated that, ...I was imprisoned and under arrest for 11 days by the local police until I paid their money. It is shocking. ...And it was not money that I owed them either. They owed me. They made it up.

\subsection{Management Control}

Management control was raised as an issue and reflected two aspects, one HR staff and the other payments and communication with other staff. In terms of HR Staff, this is 
demonstrated by one respondent (2) who specified that, ...corruption is not only anticipated, but also encouraged, as no one else has a chance to win contracts unless it has already been determined by the powers to be. Another respondent (6) suggested that, ...When you leave work without their permission it can be catastrophic. They seem to think that they own you no matter what. And top management buy into this. It is not their culture, but they are just as bad. Another respondent (14) indicated that, ...management control everything. We do what they say or we get punished through demands for money. It does make you go quiet after you lose all your wages though. Another respondent (5) suggested that, ...We are not allowed to walk out of the compound, but how do we get food or medication when you get ill? Security stops us.

In terms of Service Payments, one respondent (11) indicated that, ...towards the end of the month. They come then and demand money. If you need a permit to travel, you have to pay. If you need to see the doctor, you have to pay. If you need any "services" you have to pay. Another respondent (9) suggested that, ...if we have to go to any government service, then all the costs are tallied for you to pay at the end. No pay - no service. That's the honest truth here... Supporting this, another respondent (2) advised that, ... if you haven't paid the travel cost, you are forced to walk to work and docked pay too. This is not in my contract, but they still expect you to pay for it.

In terms of Communication, one respondent (13) indicated that, ... They won't put anything in writing, except money demands. Another respondent (11) suggested further that, ...they tell us in writing what we need to do, but they won't listen to you if you object to anything. Another respondent (10) stated that, ...we are expected to do what we're told, or we get punished. Like, when I had an accident and wanted to report it in writing, someone from HR came and said its not in the contract and if we wanted it, we need to pay for the translation and the legal bill. This is an accident report. It's very difficult here.

\subsection{Cost Issues}

Cost issues were raised that illustrate the effect of ongoing corruption practices. In terms of Work, this is typified by one respondent (7) stated that, ...It's a shame, but working for a company that makes you work 18 hours a day doesn't make it right that they pay and you pay no tax. The hourly rate is less than in the UK. Another respondent (9) indicated that, ...The company tells us that we cost so much money they have to send us to work these long hours. Another respondent (10) suggested that, ...Sometimes, they sell us to another contractor, especially because their work contract ends. That's not right is it?, we have no choice in the matter.

In terms of Transport, one respondent (14) indicated that,...The company pays for the air-fares, puts us up in accommodation and transports us back and for to work. WE owe them a lot. Plus we pay someone to introduce us at the beginning to get the join in [...]. But its not right that after three years I still owe them money. Its not right at all. The company doesn't care as long as I go to work. Another respondent (6) suggested that,...There's not enough of us, so we end up doing more than expected. Sometimes 15 or 18 hours a day. It's very dangerous. Our friends don't like it, I don't like it, but if you don't you end up in a jail.This is 
further supported by another respondent (12) who stated that, ...whatever happens you have to report for work and be there all day. If you need to go somewhere, they take our pay, and you have to pay for the travel and any arrangements - even if it is work related. Another respondent (8) stated that, ...sometimes there was not enough transport [space] so we had to walk the $5 \mathrm{Kms}$ to work - there and back. If you were late you lost a half-day's pay. If you complained you lost two days and more sometimes.

In terms of Financial Issues one respondent (8) affirmed that, ...anything was possible, deductions for water given during the day even. Other aspects included food during work hours, costs associated with specialist PPE was another problem. Another respondent (11) stated that, ...many times I have had to go barefoot because the bulls (wellington boots) were not available. There were little or no gloves given out - except to very special people. People who controlled us. Another respondent (3) suggested that, ...when we worked at height even at night - there were no ropes - too costly or not enough of them. Some people died. Another respondent (5) advised that,...sometimes we end up owing the company. How is that possible, when we are working 12 hours or more a day.

In terms of Reputation, one respondent (9) indicated that, ...I really won't be working for this company again. It's just not good enough. Another respondent (4) suggested that, ...I will make sure that I tell the authorities back in the UK what the recruitment company did and how it turned out. It is wrong, they lied and then took money from us all. Another respondent (5) intimated that, ...this can't be happening with every company here. If it is it really is a mess. I'll never work here again.

\subsection{Documentary Issues}

Documentary issues are an important focus for, as the evidence speaks to ways in which corruption can be detected and therefore controlled. In terms of a Passport, this is personified by one respondent (12) indicated that, ...taking the passport was one thing, another was trying to get it back. They demanded money to get it back. Eventually I did get it, but it cost me a lot. Another respondent (8) signified that, ...I couldn't get out of the country because my passport was locked up by [HR]. They wouldn't listen to me, until I paid what they wanted. Another respondent (1) advocated that,...They [HR] said that there is a security fee that is unpaid, so they won't release my passport to me. I am very disappointed.

In terms of the Contract, one respondent (8) suggested that, ...Even when the contract had run out, we had to stay working for no pay until "administrative" matters were sorted. This took some time, sometimes over three months and in many cases over 6 months - all without pay. Another respondent (3) indicated that, ...they [HR] make it so difficult to get away from here. They demand so much money, I don't know who's working for whom...Supporting this, another respondent (10) signified that, ...we make no money here. I can't afford to send any home because they [HR] are always coming to us with some money demand for something we have or shouldn't have done. It's crazy here... Another respondent (7) stated that, ...I was expected to pay my own flight home. Again not part of the contract. 
In terms of Permits, one respondent (6) affirmed that, ...I left the company after the last payday and I went to a friends place to live until I could get my documents to leave the country. I was there for 4 months. I paid a lot of money after their demand, but it was not on company letters. Another respondent (14) indicated that,...Because I couldn't read it properly and provide what they wanted, they kept demanding and it went up. The police was not interested...Another respondent (11) specified that, ...Documents are given to ex-workers include a Demand for Money before any permits are issued, using Documentary evidence from past employees. It is just not right.

\subsection{Financial Demands}

Financial demands appear to be necessitated through direct means - personable or by documentary means - designed to restrict an individual's movement, health, work practices or home enjoyment. In terms of Government Employees, this is represented by one respondent (7) who specified that... they give us written demands - plain background - no letterhead, no signatures of staff presently employed, no telephone numbers. Just a demand. It is not right. How can I get a permit this way. Another respondent (4) indicated, that ...demand letters from a subsidiary of the company, without signatures, phone numbers or company email addresses can arrive at your place of work. They [company] knows this happens. They demand money we can't hope to pay. The authorities don't care. If we go to the police they end up jailing us for a few days for bothering them, because we can't show them any ID. Another respondent (11) suggested that, ...no matter who you contact there, they won't do anything for you without settling up...

In terms of HR Staff, one respondent (2) suggested that, ... if you want to transfer to another job - even on the same site - they will find reasons not to grant the move - unless you pay them for it. Another respondent (9) stated that, ...HR people asking for upfront "service" payments to allow paperwork to proceed. This always happens - especially at the end of the month. Another respondent (2) detailed that, ...they [HR] will always follow you around the admin block for money. It's very scary here. Another respondent (3) indicated that, ...HR staff were found to be using our personal data to open accounts and then transferring money to their accounts. Is this normal?

In terms of Accommodation, one respondent (13) signified that, ...Accommodation personnel were always asking for money regularly to "help" get things for ourblock - which had already been allocated by the project to us. Another respondent (10) indicated that, ...The Company keeps making us pay for accommodation but won't pay us back at the end of the month. Another respondent (5) suggested that, ...We can't do without accommodation, but it is the little things like paying for keys or water that they make money on us with.

\section{Discussion of Outcomes}

The results suggest that corruption is present at lower organisational levels and appeared to be tolerated by company management. Of concern was the lack of transparency in the managerial positioning of organisation, which should create some pressure from the client - 
who appears to remain oblivious, ambivalent and unresponsive to the situation. In terms of the main themes, the present situation is revealed as:

4.1 Country Issues - of real disquiet is the establishment of corruption acceptance not only at company levels but also across industries. There does not appear to be any prevention measures at work (Heffernan \& Kleinig, 2004), which leaves lower management and ordinary workers at risk from the focus of corruption practices (Aguilar, Gill \& Pino, 2000). Of further concern was the level of demands made on lower staff by middle ranking HR staff for aspects that have or should have been provided by the company free and without exception.

4.2 Company Policies - Companies have a right to manage their affairs in the way that suits their specific requirements. However, lower staff need to be protected from corruption practices, as their position in the organisation is considered relatively weak. Management policies need to be utilised more effectively to counteract corruption within the organisation. This is a failure of management (Bourne, Neely, Platts\& Mills, 2002), indifference to good governance practices (Sohail\&Cavill, 2008) and shows a lack of respect for fellow workers (Ngacho\& Das, 2014). This affects company credibility (Alcañiz, Cáceres, \& Pérez, 2010), personnel integration (Zarkada-Fraser \&Skitmore, 2000) and appropriate levels of organisational trust (Schoorman, Mayer\& Davis, 2007).

4.3 Management Control - Top management do not appear to be in control of lower management staff or do not want to act to prevent or resist any overt corruptive practices. This shows a lack of top management leadership (James, 2005), lack of care and attention to staff welfare (Sönmez, Apostopoulos, Tran \&Rentrope, 2013), and illustrates company incapability to control illegal staff practices whilst failing to develop appropriate methods to counter and suppress corruptive practices in an employee-abusive organisation (Lutgen-Sandvik\& McDermott, 2008).

4.4 Cost Issues-There does not appear to be effective cost management practices at site as ancillary staff (HR) appear to raise the cost of administration for their own benefits (Vee \& Skitmore, 2003) and also inflate the overall project cost by their financial demands (Zinnbauer\& Dobson, 2008). This does little to create a more efficient management operation (Olawale\& Sun, 2010), incorporate consistent responsibility (Brown, Schmied and Tarondeau, 2002) and also denigrates worker/staff relations (Taylor, 2000).

4.5 Documentary Issues-There is a demonstrated issue related to monitory demands and documentary provision under the law. Consequently, the overt corruptive practices are not just contained within the organisation but administratively extend outwards to staff in both private and public organisations obviating standards of fair-trading (Ali \& Kamaruzzaman, 2010). This also shows little respect for personnel, acts against fair-play and illustrates how management can use private administrative documents for their benefit, whilst a lack of proper communication (Olander \& Landin, 2005) inhibits good governance.

4.6 Financial Demands-HR Staff (especially) making demands on other weaker staff affect not only the internal relationships negatively but also externally through diminishing 
company English reputation. As a consequence of employing corruptive practices this also leads to flagrant issues of trust. Consequently, applying such demands appears to have created an atmosphere of mistrust and unease (Nichols, 2011) leading to a negative focus on cultural norms and destructive organisational habits (Cavill\&Sohail, 2005).

\section{Conclusion}

Ongoing corruptive practices in Qatar focusing on workers/individuals who are powerless to protect themselves are denied appropriate protection. There is also demonstrably a lack of professional ethics relating to the HR management (Ali, 2010) in the construction project (Helgadottir, 2008). Transparency may help reduce corruption (Luo, 2000), but so does reporting the corruption event or report the event in the media. Qatar lacks the want or capability of reporting. Corruption has been practiced in different arenas and disciplines, but is still a characteristic of the operative project functional areas (Brown \&Cloke, 2011).

It would appear that mitigating corruptive practices (Graycar\& Sidebottom, 2012) would help reduce tensions within the company (Zou, 2006) leading to more effective engagement in construction management (Lester, 1999) whilst helping to reduce costs (Ahiaga-Dagbui \& Smith, 2014) associated with the project operation.

\section{References}

Aguilar, M.A. Gill, J., \& Pino, L. (2000). Preventing Fraud and Corruption in World Bank Projects. Washington, US:The World Bank.

Ahiaga-Dagbui, D.D., \& Smith, S.D. (2014). Rethinking construction cost overruns: cognition, learning and estimation. Journal of Financial Management of Property and Construction. 19(1), 38-54. http://dx.doi.org/10.1108/JFMPC-06-2013-0027

Olawale, Y.A. Sun, M. (2010).Cost and time control of construction projects: inhibiting factors and mitigating measures in practice. Construction Management and Economics, 28, 509-526. http://dx.doi.org/10.1080/01446191003674519

Alcañiz, E.B.Cáceres, R.C., \& Pérez, R.C. (2010). Alliances Between Brands and Social Causes: The Influence of Company Credibility on Social Responsibility Image. Journal of Business Ethics. October 2010. 96 (2). 169-186.

Ali, A.J. (2010). Islamic challenges to HR in modern organizations. Personnel Review, 39(6), 692-711. http://dx.doi.org/10.1108/00483481011075567

Ali A.S., \& Kamaruzzaman, S.N. (2010). Cost performance for building construction projects in Klang valley. Journal of Building Performance, 1. 110-118.

Al-Sabah, R., Menassa, C.C., \& Hanna, A. (2014).Evaluating Significant Risks In The Middle East North Africa (Mena) Construction Projects From Perspective Of Multinational Firms.Construction Management and Economics, 32(4), 382-402. http://dx.doi.org/10.1080/01446193.2014.884281 
Askari, H., Rehman, S.S., \& Arfaa, N. (2010). Corruption and Its Manifestation in the Persian Gulf.Edward Elgar Publishing, Cheltenham, UK.[Online] Available: www.bbc.com/news/world-europe-32897066

Bailey, K.D. (2008). Methods of Social Research. $\left(4^{\text {th }}\right.$ Ed). The Free Press, NY, US.

Balshem, M. (1991). Cancer, Control and Causality: Talking about Cancer in a Working-Class Community. American Ethnologist, 18(1), 152-172. http://dx.doi.org/10.1525/ae.1991.18.1.02a00070

Benn, N. Buckingham, S. Domingue, J., \& Mancini, C. (2008). Ontological Foundations for Scholarly Debate Mapping Technology.In 2nd International Conference on Computational Models of Argument (COMMA '08), Toulouse, France.

Bourne, M., Neely, A., Platts, \& K. Mills, J. (2002). The success and failure of performance measurement initiatives.International Journal of Operations \& Production Management, 22(11), 1288-1310. http://dx.doi.org/10.1108/01443570210450329

Brown, E., \& Cloke, J. (2011). Critical perspectives on corruption: an overview. Critical perspectives on international business, $7(2), \quad 116-124$. http://dx.doi.org/10.1108/17422041111128203

Brown, K. Schmied, H., \& Tarondeau, J. (2002). Success Factors in R\&D: A meta-analysis of the empirical literature and derived implications for design managers. Design Managers $\begin{array}{llll}\text { Journal. } & \text { Academic } & \text { Review, } & \text { 72-87. }\end{array}$ http://dx.doi.org/10.1111/j.1948-7177.2002.tb00013.x

Bryman, A. (2012). Social Research Methods. $\left(4^{\text {th }}\right.$ Ed). Oxford University Press, Oxford, UK.

Buston, K. (1999). NUD*IST in action: its use and its usefulness in a study of chronic illness in young people. In Bryman A., \& Burgess R.G. (Eds.) Analysis and Interpretation of Qualitative Data.Sage Publications, London, UK.

Carman, J.M. (1990). Consumer Perceptions of Service Quality: An Assessment of the SERVQUAL Dimensions. Journal of Retailing, 66(1), 33-55.

Cassell, C., \& Symon, G. (2004). Essential Guide to Qualitative Methods in Organizational Research, Sage Publications, London, UK.

Cavill, S., \& Sohail, M. (2005). Improving public urban services through increased accountability. Journal of Professional Issues in Engineering Education and Practice, American Society of Civil Engineers, 131(4), 263-273.

Cayla, J., \& Eckhardt, G.M. (2007). Asian Brands without Borders: Regional Opportunities and Challenges. International Marketing Review, 24(4), 444-456. http://dx.doi.org/10.1108/02651330710761017

Chang, C.Y. (2015). Risk-bearing capacity as a new dimension to the analysis of project governance.International Journal of Project Management, 33(6), 1195-1205. http://dx.doi.org/10.1016/j.ijproman.2015.02.003 
Coyne, I.T. (1997). Sampling in qualitative research: purposeful and theoretical sampling; merging or clear boundaries? Journal of Advanced Nursing, 26(3), 623-30.

Crouch, M. McKenzie, H. (2006). The logic of small samples in interview-based qualitative research.Social Science Information, 483-499. http://dx.doi.org/10.1177/0539018406069584

Daniels et al. (2007). The Successful Resolution of Armed Hostage/Barricade Events in Schools: A Qualitative Analysis. Psychology in the Schools, 44(6), 601-613. http://dx.doi.org/10.1002/pits.20250

Duranti, A. (2007). Transcripts, like Shadows on a Wall. Mind, Culture, and Activity, 13(4), 301-310.

ey.com, (2015).[Online] Available: http://www.ey.com

Fink, A.S. (2000). The Role of the Researcher in the Qualitative Research Process.A Potential Barrier to Archiving Qualitative Data. Forum: Qualitative Social Research, 1(3).

Glaser, B.G. (2004). Remodeling Grounded Theory. The Grounded Theory Review: An international Journal, 4(1), 1-24.

Glaser, B.G. (1992a). Basics of grounded theory analysis: Emergence vs. forcing. Mill Valley, Sociology Press, CA, US.

Glaser, B.G., \& Strauss, A.L. (1967). The Discovery of Grounded Theory: Strategies for Qualitative Research, Aldine, Chicago, US.

Gonzalez, C. (2008). Conceptions of, and approaches to, teaching online: a study of lecturers teaching postgraduate distance courses. Higher Education, 57(3), 299-314. http://dx.doi.org/10.1007/s10734-008-9145-1

Gray, J., \& Wilcox, B. (1995). Good Schools, Bad Schools, Open University Press, UK.

Graycar, A. Sidebottom, A. (2012). Corruption and control: a corruption reduction $\begin{array}{llll}\text { approach. Journal of } \quad \text { Financial } & \text { Crime, } & \text { 19(4), } & \text { 384-399. }\end{array}$ http://dx.doi.org/10.1108/13590791211266377

Guba, E.G. (1981). Criteria for assessing the trustworthiness of naturalistic inquiries. Educational Communication and Technology Journal, 29, 75-91.

Guest, G., Bunce, A., \& Johnson, L. (2006). How Many Interviews Are Enough? An Experiment with Data Saturation and Variability. Field Methods, 18(1), 59-82. http://dx.doi.org/10.1177/1525822X05279903

Harrel, G.D., \& Fors, M.F. (1995). Marketing services to satisfy internal customers.Logistics Information Management, 8(4), 22-27. http://dx.doi.org/10.1108/09576059510091887

Harwood, T.G., \& Garry, T. (2003). An Overview of Content Analysis.The Marketing Review, 3(4), 479-498. http://dx.doi.org/10.1362/146934703771910080 
Healy, M. Perry, C. (2000). Comprehensive criteria to judge validity and reliability of qualitative research within the realism paradigm.Qualitative Market Research: An International Journal, 3(3), 118-126.

Heffernan, W.C., \& Kleinig, J. (2004). Private and Public Corruption. Roman and Littlefield Publishers, Oxford, UK.

Helgadottir, H. (2008). The ethical dimension of project management. International Journal of Project Management, 26(7), 743-748. http://dx.doi.org/10.1016/j.ijproman.2007.11.002

Hill, C.E. Thompson, B.J., \& Williams, E.N. (1997). A guide to conducting consensual qualitative research. The Counseling Psychologist, 25(4), 517-572. http://dx.doi.org/10.1177/0011000097254001

Hooker, J. (2009). Corruption from a cross-cultural perspective. Cross Cultural Management: An International Journal, 16(3), 251-267. http://dx.doi.org/10.1108/13527600910977346

International Anti Corruption Resource Center. (2015). [Online] Available: http://iacrc.org/ James, P. (2014). Managerial Challenges Impacting on Contractor Led Tunnel TBM Design: A Kingdom of Saudi Arabia Metro Project. Engineering Management Review, 3(2).

James, P. (2014). Project Financial Management and Modern Financial Slavery: The Case of a KSA Metro Project Start-up. Asian Journal of Finance \& Accounting, 6(2), 278-300. http://dx.doi.org/10.5296/ajfa.v6i2.6297

James, P., \& James, T. (2011). Qualitative Research Methods for Health Services, Megellan UK Press, London, UK.

Khatib, L. (2013). Corruption in Qatar?The Link between the Governance Regime and Anti-Corruption Indicators, Working Paper No. 40, ERCAS Working Papers, ERCAS.

Kim, (2011). The Pilot Study in Qualitative Inquiry: Identifying Issues and Learning Lessons for Culturally Competent Research. Qualitative Social Work, 10(2), 190-206. http://dx.doi.org/10.1177/1473325010362001

Koerber, A., \& McMichael, L. (2008). Qualitative Sampling Methods A Primer for Technical Communicators.Journal of Business and Technical Communication, 22(4), 454-473. http://dx.doi.org/10.1177/1050651908320362

Lester, J. (1999). How to Minimise Corruption in Public Works Construction Contracts. Journal of Financial Crime, 7(2), 161-169. http://dx.doi.org/10.1108/eb025934

Lincoln, Y. S., \& Guba, E. G. (1985). Naturalistic inquiry, Sage, Beverly Hills, US.

Luo, Y. (2004). An organizational perspective of corruption. Management and Organization Review, 1(1), 119-154.

Lutgen-Sandvik, P., \& McDermott, V. (2008). The Constitution of Employee-Abusive Organizations: A Communication Flows Theory. Communication Theory, 18, 304-333. 
Moubaydeen, S., Pope, J., Tuck, J., Walker, M., \& Mackay, N. (2013).Construction and projects in Qatar: overview. [Online] Available: Dentons \& Co, Qatar, practicallaw.com/5-519-5882.

Ngacho, C., \& Das, D. (2014). A performance evaluation framework of development projects: An empirical study of Constituency Development Fund (CDF) construction projects in Kenya. International Journal of Project Management, 32, 492-507. http://dx.doi.org/10.1016/j.ijproman.2013.07.005

Nichols, P.M. (2011). The Psychic Costs of Violating Corruption Laws. Vanderbilt Journal of Transnational Law, 45, 145-210.

OECD. (2015). [Online] Available:http://www.oecd.org/corruption/

Olander S., \& Landin, A. (2005). Evaluation of stakeholder influence in the implementation of construction projects. International Journal of Project Management, 23(4), 321-328. http://dx.doi.org/10.1016/j.ijproman.2005.02.002

Onwuegbuzie, A. J., \& Leech, N. L. (2007). Sampling Designs in Qualitative Research: Making the Sampling Process More Public. The Qualitative Report, 12(2), 238-254.

PWC. (2015).[Online] Available:http://www.pwc.com/crimesurvey

Ramady, (2014). State of Qatar: Risk Analysis, Political, Economic and Financial Country Risk, Springer Books, 117-140.

Reeves, T.K., \& Harper, D. (1981).Surveys at Work. London: McGraw-Hill, UK.

Reisman, C. K. (1993).Narrative Analysis, Sage, London, UK.

Ritchie, J., \& Lewis, J. (2003). Qualitative Research Practice: A Guide for Social Science Students and Researchers. Sage Publications, London, UK.

Ryan, G.W., \& Bernard, H.R. (2003). Techniques to Identify Themes. Field Methods, 15(1), 85-109. http://dx.doi.org.10.1177/1525822X02239569

Schoorman, F.D., Mayer, R.C., \& Davis, J. H. (2007). An Integrative Model Of Organizational Trust: Past, Present, And Future. Academy of Management Review, 32(2), 344-354.

Sohail, M., \& Cavill, S. (2008). Accountability to Prevent Corruption in Construction Projects. J. Constr. Eng. Manage, 134(9), 729-738.

Sönmez, S., Apostopoulos, Y., Tran, D., \& Rentrope S. (2013). Human rights and health disparities for migrant workers in the UAE. Health and Human Rights Journal, 13(2), August.

Stansbury, N. (2005). Exposing the foundations of corruption in construction. In: Global Corruption Report (2005) Special Focus: Corruption in Construction and Post Conflict Reconstruction. Transparency International. [Online] Available: 


\section{Macrothink}

Journal of Management Research

ISSN 1941-899X 2015, Vol. 7, No. 5

http://www.transparency.org/whatwedo/publication/global_corruption_report_2005_corrupti on_in_construction_and_post_conflict

Taylor, M. (2000). Informal Conflict Resolution: A Workplace Case Study. [Online] Available: Mediate.com, September.

TI. (2015). Transparency International.[Online] Available: http://www.transparency.org/cpi2014/results

UNCAC (2005). [Online] Available: https://www.unodc.org/unodc/en/treaties/CAC/

Tull, D.S., \& Hawkins, D.I. (1990). Marketing Research: Measurement and Method. Macmillan, UK.

Vee, C., \& Skitmore, M. (2003). Professional Ethics in the Construction Industry.Journal of Engineering, Construction and Architectural Management, 10(2), 117-127.

Walsh, S. P., White, K. M., \& Young, R. M. (2008). Over-Connected? A Qualitative Exploration of the Relationship between Australian Youth and Their Mobile Phones.Journal of Adolescence, 31(1), 77-92. http://dx.doi.org/10.1016/j.adolescence.2007.04.004

Windapo. (2013). Fundemantals of Construction Management.[Online] Available: https://en.wikipedia.org/wiki/United_Nations_Convention_against_Corruption

World Bank. (2004). [Online] Available:www.worldbank.org/

Yin, R.K. (1994).Case study research: Design and methods (2nd ed.). Sage Publications, Newbury Park, CA, US.

Zarkada-Fraser, A., \& Skitmore, M. (2000). Decisions with moral content: collusion. Construction Management and Economics, 18, 101-111.

Zinnbauer, D. \& Dobson, R. (Eds). (2008). Global corruption report: Corruption in the water sector, Cambridge University Press, UK.

Zou, P. (2006).Strategies for Minimizing Corruption in the Construction Industry in China. Journal of Construction in Developing Countries, 11(2), 15-29. 